\title{
Behçet Syndrome and Hypogonadotropic Hypogonadism: case
}

\section{report}

\author{
G Calcagno*1, A Vitale ${ }^{1}$, F La Torre ${ }^{1}$, S Carcione ${ }^{1}$, M Valenzise ${ }^{2}$, C Fede ${ }^{1}$ and \\ T Arrigo $^{2}$
}

Address: ${ }^{1}$ Deparment of Pediatrics, Pediatric Rheumatology, Messina, Italy and ${ }^{2}$ Deparment of Pediatrics, Pediatric Endocrinology, Messina, Italy * Corresponding author

\author{
from $15^{\text {th }}$ Paediatric Rheumatology European Society (PreS) Congress \\ London, UK. 14-17 September 2008 \\ Published: 15 September 2008 \\ Pediatric Rheumatology 2008, 6(Suppl I):P264 doi:10.II86/I546-0096-6-SI-P264
}

This abstract is available from: http://www.ped-rheum.com/content/6/SI/P264

(C) 2008 Calcagno et al; licensee BioMed Central Ltd.

\section{Background}

Behçet Disease (BD) is a sistemic chronic vasculitis

\section{Clinical case}

A sixteen year old boy presented, three years before, gastrointestinal (abdominal pain, vomiting, diarrhea) and neurologic symptoms (headache, diplopia, ataxia, VI nerve paralysis), with fever, oral and genital aphtosis. Laboratory tests showed increased ESR, CRP). He carried B51HLA. Physical examination showed svere obesity, pseudomicropenis, rare pubic hair, pubertal stage G2P2. Thus BD was diagnosed. Treatment with corticosteroids and antiplatelet agents was started.

After 2 months, azathioprine and infliximab were added; but biological agent was stopped, because of adverse reactions; thus thalidomide was started. After the diagnosis, the patient presented a progressive weight increase (BMI 39) and a delayed puberty. He presented acanthosis nigricans, pseudoginecomasty, pseudomicropenis with testicular volumes of $2 \mathrm{~mL}$, bone age was of 14.5 years (vs 15.6 cronologic age). The boy underwent several endocrinological tests that showed a short increase of GH to glucagon and clonidine Tests, low testosterone levels, a short increase of gonadotropins to LHRH test, normal answer to IGF-I generation test, normal glucidic tolerance with severe and prolonged hyperinsulinism.

\section{Conclusion}

We suggest that the boy had presented a neurologic involvement, that could explain his hypogonadotropic hypogonadism. We performed a cerebral MRI and a dosage of anti-hypophysis antibodies, which are normal.

Although no cases of BD and hypogonadotropic hypogonadism have been described, we report this case for the numerous patogenetic hypotheses that it could generate.

\section{References}

I. Gül A: "Behçet's disease as an autoinflammatory disorder". Curr Drug Targets Inflamm Allergy 2005, 4(I):8I-3. 